\begin{tabular}{|c|c|}
\hline Proceeding of the $9^{\text {th }}$ ICEE Conference 3-5 April 2018 & NRA \\
Military Technical College \\
Kobry El-Kobbah, \\
Cairo, Egypt
\end{tabular}

NRA-2

\title{
Thermal Decomposition Properties of Gamma-Irradiated Polyvinyl Alcohol (PVA)/Methyl Cellulose (MC) Blends
}

\author{
Magdy M. Senna ${ }^{1} *$, Reham H. Helal ${ }^{1}$, Tahia A. Mostafa ${ }^{2}$, Abdel Wahab M. El-Naggar ${ }^{1}$
}

\begin{abstract}
Poly(vinyl alcohol)/ methyl cellulose (PVA/MC) blends, at different ratios were prepared into films by solution casting using, water as a common solvent, and gamma irradiated at various doses. Thermogravimetric analysis (TGA) and differential scanning calorimetry (DSC) were used to study the thermal properties of gamma irradiated PVA/MC blends. It is expected that these methods would enable to understand the effect of gamma irradiation on the mechanism of thermal decomposition. The kinetic parameters such as energy of activation $\left(E_{a}\right)$ and regression $r^{2}$ for the thermal decomposition were determined by three different methods. In the present work, the Coats-Redfern, Broido and Horowitz-Metzger methods were applied. The results indicated that the $E_{a}$ and $r^{2}$ values of the gamma irradiated PVA/MC blends as determined by the three methods were comparable.
\end{abstract}

\section{Keywords:}

Polyvinyl alcohol; Methyl cellulose; Gamma Radiation; Thermal properties; Kinetic studies

\footnotetext{
${ }^{1}$ Radiation Chemistry Department, National Center for Radiation Research and Technology, B.O. Box 29 Nasr City, Atomic Energy Authority, Cairo Egypt ${ }^{2}$ Chemistry Department, College for Girls, Ain Shams University, Cairo, Egypt *Correspondence to: Magdy M. Senna, Email: magdysenna@hotmail.com
} 

Military Technical College
Kobry El-Kobbah, Cairo, Egypt

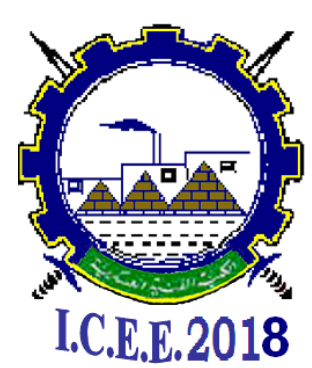

$9^{\text {th }}$ International Conference on

Chemical \& Environmental

Engineering

3-5 April 2018

\section{Introduction}

Polymer blending constitutes a useful method for modifying the physico-chemical properties of polymeric materials. Some of the polymer blends exhibit unusual and unexpected properties from the homopolymers. An important property of a polymer blend is the miscibility of its components, because it affects the mechanical, morphology, permeability and degradation properties [1]. Extensive studies have been carried out on the miscibility in multi-component polymer systems [2-5].

Polyvinyl alcohol (PVA) as a water-soluble polymer was used in different practical applications because of its easy preparation, excellent chemical resistance physical properties and because it is completely biodegradable [6]. On the other hand, cellulose, an abundant natural carbohydrate, is not soluble in water due to its high rigidity and insolubility in most solvents. In addition, the hydroxyl groups of the anhydroglucose units, which form strong hydrogen bonding, are responsible for its crystallinity. To solubilize the crystalline cellulose, hydrophobic groups such as methyl or hydroxypropyl moieties are introduced in the cellulose backbone [7-11]. In methyl cellulose (MC), one of the best-known modified cellulose, some of the hydroxyl groups are replaced by methoxyl groups. The conversion of some of the hydroxyl groups of cellulose into hydrophobic groups attenuates the hydrogen bonding, thus decreasing the crystallinity and increasing the water solubility. Since MC is a polyhydroxy polymer, it can be chemically crosslinked with a dialdehyde in the presence of a strong acid to produce hydrogels [12-17]. So far, little was known about the structure of the chemically crosslinked MC hydrogels.

The synthesis and characterization of PVA/MC blends gained an attention in literature due to its important usages in different fields. The effect of hyaluronic acid (HA) on the thermogelation and biocompatibility of its blends with methyl cellulose was reported [18]. It was found possible to obtain $\mathrm{MC} / \mathrm{HA}$ blends showing a rheological behavior typical of a viscous solution at $20^{\circ} \mathrm{C}$ and of a weak gel at $37^{\circ} \mathrm{C}$ only when blending $\mathrm{MC}$ with low molecular weight HA. In addition, the optimized blends, in terms of rheological properties and biocompatibility, proved to be able to control and prolong bovine serum albumin release by a combined mechanism of platform dissolution and drug diffusion. The miscibility behavior and physico-mechanical properties between methyl cellulose (MC) of different molecular weights and poly(acrylic acid) (PAA) were studied by viscometry, differential scanning calorimetry (DSC), thermal gravimetric analysis (TGA), tensile strength and scanning electron microscopy (SEM) using water as a solvent [19]. It was found that the MC/PAA blends exhibit good mechanical properties, thermal stability, characteristics of a MC-PAA polymer network. SEM of the blends showed no phase separation, when compared with the pure MC and PAA. Interpenetrating network 


\author{
Military Technical College \\ Kobry El-Kobbah, \\ Cairo, Egypt
}

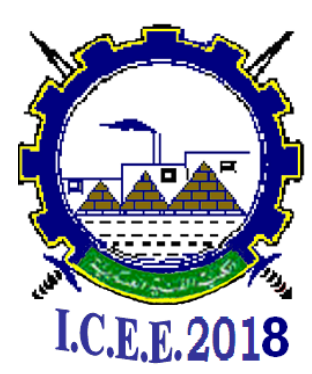

$9^{\text {th }}$ International Conference on

Chemical \& Environmental

Engineering

3-5 April 2018

(IPN) blend microspheres of poly(vinyl alcohol) (PVA) and methyl cellulose (MC) were prepared to study their controlled release of two drugs viz., water soluble losartan potassium (LK) and water-insoluble clopidogrel bisulphate (CB) that belong to the class of antihypertensive drugs [20]. The synthesis of methyl cellulose (MC) from chemically purified cellulose extracted from sugarcane bagasse was carried out with dimethyl sulfate (DMS) in the presence of sodium hydroxide and acetone as solvent under heterogeneous conditions [21]. It was concluded that the synthesized methyl cellulose enhanced the value to this abundant agro-industrial residue and may extend its range of biomedical applications.

In the present study, thermogravimetric analysis of the gamma irradiated PVA/MC blends were carried out. The energy of activation $\left(\mathrm{E}_{\mathrm{a}}\right)$ for the major decomposition step and the regression coefficient $\left(\mathrm{r}^{2}\right)$ were determined by employing the Coats-Redfern [22], Broido method [23] and the approximation method of Horowitz-Metzger [24] and the results were compared. In addition, the thermal of properties of glass and melting temperatures were studied by differential scanning calorimetry (DSC).

\section{Experimental}

\subsection{Materials}

Polyvinyl alcohol (PVA) used in this study was a laboratory-grade chemical and purchased from Backer Chemical Co., USA. It was in the form of powder, fully hydrolyzed and has an average molecular weight of 125,000 g/mol. Methyl cellulose (MC) was a laboratory-grade chemical and purchased from Sigma Company, Canada, and (CAS) 9004-67-5.

\subsection{Preparation of poly (vinyl alcohol) /methyl cellulose blends}

The preparation of poly (vinyl alcohol)/methyl cellulose (PVA)/(MC) blends was carried out as follows: Aqueous polymer solutions (10 wt $\%$ ) of PVA and MC were prepared by dissolving the polymer powders in water and heating at $80^{\circ} \mathrm{C}$ under continuous stirring. The blend films were obtained by solution casting of polymer blends on a glass plate and air-drying for $72 \mathrm{~h}$ at room temperature.

\subsection{Gamma Irradiation}

Irradiation to the required doses was carried out in the Co-60 gamma cell at a dose rate of $2.4 \mathrm{kGy} / \mathrm{h}$ in air. The gamma cell facility was installed at the National Center for Radiation Research and Technology, Cairo, Egypt. The exposure time was adjusted to achieve the required absorbed doses. 
Military Technical College

Kobry El-Kobbah,

Cairo, Egypt

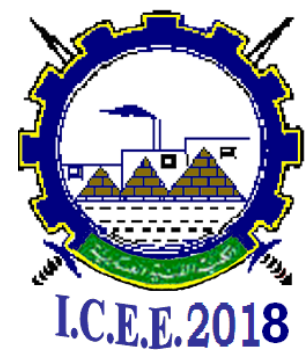

$9^{\text {th }}$ International Conference

on

Chemical \& Environmental

Engineering

3-5 April 2018

\subsection{Gel fraction (\%) and swelling (\%)}

Samples of the prepared polymer blends were accurately weighed $\left(\mathrm{W}_{\mathbf{o}}\right)$ and then extracted with distilled water using a soxhlet system and then dried in a vacuum oven at $80^{\circ} \mathrm{C}$ to a constant weight $\left(\mathrm{W}_{1}\right)$. The gel fraction was calculated according to eq. (1):

$$
\text { Gel fraction }(\%)=\left(\mathrm{W}_{1} / \mathrm{W}_{\mathrm{o}}\right) \times 100
$$

Swelling studies were conducted on PVA/MC blends as a function of irradiation dose. A known dry weight of insoluble blend $\left(\mathrm{W}_{\mathrm{d}}\right.$ ) was immersed in water up to $24 \mathrm{~h}$ at $25^{\circ} \mathrm{C}$ for each dose, the sample was removed and blotted on filter paper to remove excess water and weighed $\left(\mathrm{W}_{\mathbf{s}}\right)$, in which the percentage swelling was calculated according to eq. (2):

$$
\text { Swelling }(\%)=\left[\left(\mathrm{W}_{\mathrm{s}}-\mathrm{W}_{\mathrm{d}}\right) / \mathrm{W}_{\mathrm{d}}\right] \times 100
$$

\subsection{Thermogravimetric analysis (TGA)}

Thermogravimetric analysis was carried out using a TG-50 instrument from Shimadzu (Japan) with a heating rate of $10^{\circ} \mathrm{C} / \mathrm{min}$.

\subsection{Differential scanning calorimetry (DSC)}

DSC measurements were performed using a Shimadzu DSC-50 Calorimeter equipped with data station. A heating rate of $10^{\circ} \mathrm{C} / \mathrm{min}$ was utilized and the scans were carried out under a flowing nitrogen atmosphere at a rate of $20 \mathrm{ml} / \mathrm{min}$.

\section{Results and discussion}

\subsection{Effect of gamma radiation on PVA/MC blends}

PVA and MC are water-soluble polymers with, theoretically, have no functional groups required to achieve miscibility and the competition of hydrogen bonding. Although MC is a water-soluble polymer that give a clear and visually transparent solution, all attempts to form cast films failed. However, when PVA/MC blend solutions with low MC ratios were caste, good films were obtained and appeared transparent to visual observation. In this regard, when the ratio of MC in the polymer blends were increased beyond $20 \%$, phase separation was observed and the transparency no longer occurred.

Fig.1 shows the effect of irradiation dose on the gel fraction (\%) and swelling (\%) in water at room temperature and $\mathrm{pH}$ of 7 of $\mathrm{PVA} / \mathrm{MC}$ blends at different ratios. It can be seen that nearly complete gelation of PVA and PVA/MC blends was obtained at a dose of $20 \mathrm{kGy}$ of gamma radiation. The gel fractions (\%) at this dose of PVA and PVA/MC 


\section{Military Technical College Kobry El-Kobbah, Cairo, Egypt}

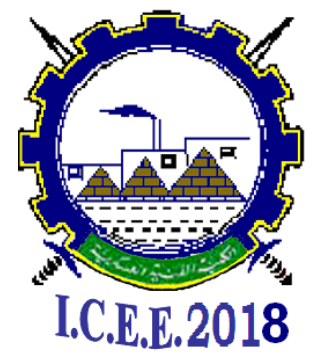

$9^{\text {th }}$ International Conference on

Chemical \& Environmental Engineering

3-5 April 2018

blends having 5, and 10\% MC were determined to be $85.0,60.5$, and $51.7 \%$, respectively. Further increase in dose up to $40 \mathrm{kGy}$, the gel fractions (\%) for the same materials were determined to be 90,68 and $57.2(\%)$, respectively. We did not use higher doses to avoid the oxidative degradation of the $\mathrm{MC}$ component. In addition to the free radical formation on backbone of polymers, it was reported that the polymerization and crosslinking occurs by the products of the radiolysis of water, which is present in appropriate quantities, as reported in the very early stage of radiation chemistry according to eq.3 [25]:

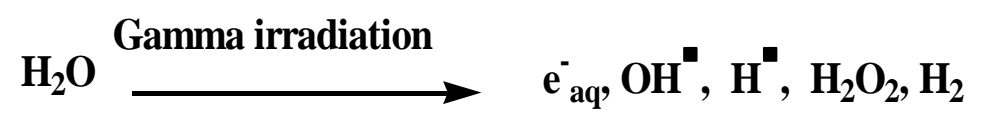

The mechanism of crosslinking of polymers in solution by gamma radiation through the formation of free radicals was also early reported [26-28].

As shown in Fig. 1, an opposite trend can be observed in the swelling (\%) properties of PVA and PVA/MC blends compared to gel fraction (\%). The swelling (\%) decreased with increasing irradiation dose, in which the crosslinking led to the restriction of the water swelling [29].

\subsection{Kinetic parameters of thermal decomposition}

A reaction rate is defined as the derivative of conversion with respect to time. In a TGA, conversion is defined as the rate of final mass loss to total mass loss corresponding to a particular stage of degradation process [30].

$$
\beta=\mathrm{W} /\left(\mathrm{W}_{\infty}-\mathrm{W}\right)
$$

Where, $\mathrm{W}_{\infty}=$ mass loss at the end of the particular stage of reaction, $\mathrm{W}=$ mass loss up to time t.

The rate of conversion in a dynamic TGA experiment at a constant heating rate can be expressed as:

$$
\mathrm{d} \beta / \mathrm{dt}=\mathrm{Q}(\mathrm{d} \beta / \mathrm{dt})=\mathrm{k}(\mathrm{T}) \mathrm{f}(\beta)
$$

Where, $\mathrm{Q}$ is the heating rate, $\mathrm{k}(\mathrm{T})$ is the rate constant and $\mathrm{f}(\beta)$ is the conversion functional relationship. Arrhenius expression, which describes the temperature dependence of the rate constant, may be expressed as:

$$
\mathrm{k}(\mathrm{T})=\mathrm{A} \exp (\mathrm{Ea} / \mathrm{RT})
$$




\section{Military Technical College \\ Kobry El-Kobbah, Cairo, Egypt}

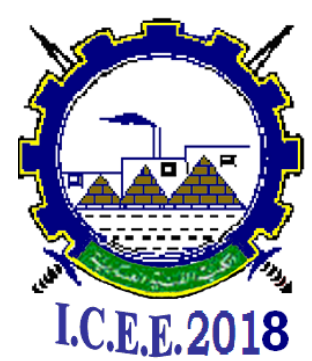

$9^{\text {th }}$ International Conference on

Chemical \& Environmental Engineering

3-5 April 2018

Where, $\mathrm{A}$ is the pre-exponential factor, Ea is the activation energy, $\mathrm{T}$ is the temperature in $\mathrm{K}$ and $\mathrm{R}$ is the Universal gas constant. The integral form of the rate equation in a dynamic heating expression experiment may be expressed as:

$$
\mathrm{g}(\beta)=\left(\mathrm{AE}_{\mathbf{a}} / \mathrm{QR}\right) \mathrm{p}(\mathrm{x})
$$

Where, $\mathrm{g}(\beta)$ is the integral form of conversion dependence function.

Several methods using different approaches have been developed for solving the integral p (x) equation. Flynn-Wall-Ozawa [31], Friedman [32], Chang [33], Kissinger and other researchers have solved this function [34]. The controversy arises due to different assumptions and approaches used for solving the function $\mathrm{p}(\mathrm{x})$ by different researchers [34].

In the present study, three different non-isothermal methods were used for the determination of the kinetic parameters of gamma irradiated PVA/MC blends. The methods employed were the Coats- Redfern, Broido and Horowitz-Metzger. For a firstorder reaction process, Coats-Redfern provided an approximation equation:

$$
\ln \left[-\ln (1-\alpha) / T^{2}\right]=-E_{a} / R T+\ln A R / \beta E_{a}
$$

where $\alpha$ is the fraction of sample decomposed at temperature T, A is a constant, $\beta$ is the heating rate, $R$ is universal gas constant and $E_{a}$ is the activation energy. Therefore, plotting $\ln \left[-\ln (1-\alpha) / \mathrm{T}^{2}\right]$ vis.1/T should give a straight line whose slope is directly proportional to the activation energy $-\mathrm{E}_{\mathrm{a}} / \mathrm{R}$.

Horowitz-Metzger provided an equation for the calculation of activation energy $\left(\mathrm{E}_{\mathrm{a}}\right)$ of polymeric substances. The equation used is:

$$
\ln [-\ln (1-\alpha)]=\mathrm{E}_{\mathrm{a}} \theta / \mathrm{RT}_{\mathrm{s}}^{2}
$$

Where $\alpha$ is the fraction of sample decomposed at temperature T, $\theta$ is the difference between the peak temperature and the temperature at particular weight loss $\left(\theta=T-T_{s}\right) ; T_{s}$ is the peak temperature; and $\mathrm{T}$ is the temperature at particular weight loss. A plot of $\ln [-$ $\ln (1-\alpha)]$ vs. $\theta$ gives approximately a straight line. From its slope the activation energy $\left(\mathrm{E}_{\mathrm{a}}\right)$ can be calculated.

Broido has developed an equation used for the calculation of activation energy $\left(E_{a}\right)$ :

$$
\ln \ln (1 / \mathrm{Y})=\left(-\mathrm{E}_{\mathrm{a}} / \mathrm{R}\right) 1 / \mathrm{T}+\mathrm{constant}
$$

Where $\mathrm{Y}$ is the fraction of the number of initial molecules that not decomposed yet 


\section{Military Technical College \\ Kobry El-Kobbah, Cairo, Egypt}

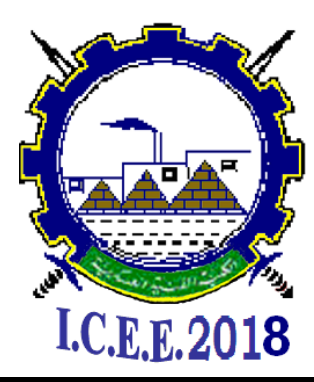

$\mathrm{Y}=\left(\mathrm{W}_{\mathrm{t}}-\mathrm{W}_{\infty}\right) /\left(\mathrm{W}_{\mathrm{o}}-\mathrm{W}_{\infty}\right)$
9 $\frac{\text { th }}{\text { International Conference }}$

on

Chemical \& Environmental

Engineering

3-5 April 2018

Where $\mathrm{W}_{\mathrm{t}}$ the weight at any time $\mathrm{t} ; \mathrm{W}_{\infty}$ is the weight at infinite time (=zero) and $\mathrm{W}_{\mathrm{o}}$ is the initial weight. A plot of $\ln \ln (1 / Y)$ vs.1/T gives approximately a straight line. The slope is related to the activation energy.

\subsection{Thermal decomposition of gamma irradiated PVA/MC blends 3.3.1. TGA thermograms}

Thermogravimetric analysis (TGA) measures the amount and rate of change in the weight of a material as a function of temperature or time in a controlled atmosphere. TGA measurements are used primarily to predict the thermal stability up to elevated temperatures.

The dissociation energies of the covalent bonds $\mathrm{C}-\mathrm{H}, \mathrm{C}-\mathrm{C}, \mathrm{C}-\mathrm{O}$ and $\mathrm{O}-\mathrm{H}$ were reported to be 414, 347, 351, 464, 389 and $293 \mathrm{~kJ} / \mathrm{mol}$, respectively [35]. According to these values, the average complete dissociation energy for PVA and MC was calculated to be 400.7 and $377.9 \mathrm{~kJ} / \mathrm{mol}$, respectively. Thus, it may be expected that PVA to possess higher thermal stability than MC and that the blends of PVA with any ratio of MC will eventually result in blends with lower thermal stability than pure PVA. However, the limited macromolecular chain mobility due to the formation of intermolecular bonds and the association between the macromolecules of the blend components is also expected to affect the thermal stability of the blends.

Fig. 2 and 3 show the TGA thermograms and the corresponding rate of thermal decomposition curves of PVA/MC blends before and after gamma irradiation to various doses, respectively. The weight loss (\%) at different heating temperatures and the kinetic temperatures taken from the corresponding TGA thermograms are summarized in Tables 1 and 2, respectively. It is clear that the major weight loss was occurred between 250$425^{\circ} \mathrm{C}$ for unirradiated or irradiated PVA/MC blends. However, during the entire heating temperatures up to $600^{\circ} \mathrm{C}$, the irradiated $\mathrm{PVA} / \mathrm{MC}$ blends showed higher thermal stability, with lower weight loss, than unirradiated PVA/MC blends. The rate of thermal decomposition reaction curves displayed similar trends and goes through one maximum indicating higher compatibility between PVA and MC in their blends. Visual observation also showed that all the solutions of PVA/MC mixture were clear at room temperature. Once again, these findings are in accordance with the kinetic decomposition temperatures ( $\mathrm{T}_{\text {onset }}, \mathrm{T}_{\text {endset }}$ and $\mathrm{T}_{\text {peak }}$ ) as shown in Table 2.

Meanwhile, the thermal stability of the PVA/MC blends was found to decrease with increasing the $\mathrm{MC}$ ratio. These findings are in accordance with the theoretical calculations according to the bond dissociation energy. In addition, these results are in accordance with the kinetic decomposition temperatures ( $T$ onset, $T_{\text {endset }}$ and $T$ peak $)$ as shown in Table 2. It can be seen that the thermal stability depends largely on the ratio of 

Military Technical College
Kobry El-Kobbah, Cairo, Egypt

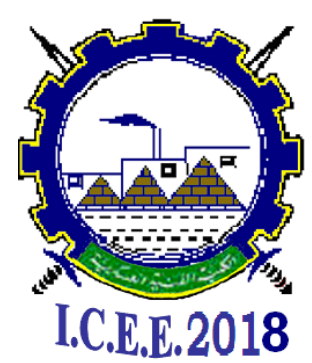

$9^{\text {th }}$ International Conference on

Chemical \& Environmental

Engineering

3-5 April 2018

MC and irradiation dose. The thermal stability decreased with increasing the ratio of MC, while it increased with increasing irradiation dose. In general, it was reported that the increase in thermal is due to the increase of crosslinking density of polymers [36-38].

\subsubsection{Kinetic parameters of TGA thermograms}

The kinetic parameters of the gamma irradiated PVA/MC blends by Coats- Redfern, Horowitz-Metzger and Broido methods were determined. The kinetic parameters include temperature range of the major decomposition stages of reaction, activation energy $\left(\mathrm{E}_{\mathrm{a}}\right)$ and the regression values $\left(\mathrm{r}^{2}\right)$.

Plots of $\log \left[\mathrm{g}(\alpha) / \mathrm{T}^{2}\right]$ vs. 1/T for gamma irradiated PVA/MC blends at different doses according to Coats-Redfern equation are shown in Fig. 4. From the slope of the straight line, the energy of activation, $\mathrm{E}_{\mathrm{a}}$ can be calculated.

The kinetic parameters of the gamma irradiated PVA/MC blends were also determined by Horowitz-Metzger method; plots of $\ln [-\ln (1-\alpha)]$ vs. $\theta$ gives an approximation to a straight line as shown in Fig. 5. $\theta$ is the difference between the peak temperature $\left(\mathrm{T}_{\mathrm{s}}\right)$ and the temperature at particular weight loss $\left(\theta=\mathrm{T}-\mathrm{T}_{\mathrm{s}}\right)$. From the slope, the activation energy $\left(\mathrm{E}_{\mathrm{a}}\right)$ can be calculated. In addition, the kinetic parameters were determined by Broido method, in which $\ln \ln (1 / \mathrm{Y})$ was plotted vs. 1/T as shown in Fig. 6. The $\mathrm{E}_{\mathrm{a}}$ and the corresponding regression values $\left(\mathrm{r}^{2}\right)$ based on the three different methods are shown in Table 3. Based on these plots and the data on Table 3, two points may be concluded:

a) In general, the activation energy of PVA/MC blends, either before or after gamma irradiation, calculated by the three methods is greatly comparable indicating the good fitting to the approximation to a straight line by these methods. The corresponding regression values $\left(\mathrm{r}^{2}\right)$ based on the three methods indicate clearly the fitting to the straight lines as shown in Table 3. As a statistical calculation, the number of samples subjected to analysis by the three methods was 36 . The regression values $\left(\mathrm{r}^{2}\right)$ between 0.91105 and 0.93430 was found to be 11 sample, whereas $\left(\mathrm{r}^{2}\right)$ between 0.95040 and 0.99586 was found to be 25 sample.

b) It can be seen that the gamma irradiated PVA/MC blends have higher energy of activation when compared to that of unirradiated blends. These findings were observed by the methods used. This is due to higher crosslink density of PVA component; indicating the higher thermal stability of the gamma irradiated blends. However, the thermal stability decreased by increasing the MC polymer component.

\subsection{Differential scanning calorimetry (DSC)}

DSC analysis has proven to be a valuable method for investigating the thermal parameters of polymeric systems. Fig.7 shows the DSC thermograms of PVA/MC blends 

Military Technical College
Kobry El-Kobbah, Cairo, Egypt

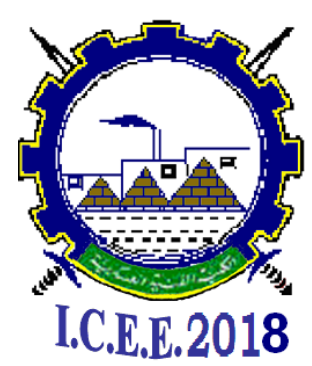

$9^{\text {th }}$ International Conference on

Chemical \& Environmental Engineering

3-5 April 2018

of various MC contents, before and after gamma irradiation at different doses. It should be noted that the $T_{g}$ was taken as the temperature of the first endothermic peak, which is the enthalpy relaxation of the amorphous part, and $\mathrm{T}_{\mathrm{m}}$ was taken as the second endothermic peak, which is due to the melting of the crystalline part of the blend. It was reported that three characteristic thermal transitions might exist for semicrystalline polymers such as MC, a glass transition for the amorphous fraction, a melting transition for the crystalline fraction and a transition due to crystallization [39]. The DSC scan of unirradiated PVA showed a relatively large and sharp endothermic curve, with a peak at $\sim 220^{\circ} \mathrm{C}$, while $\mathrm{MC}$, which is amorphous, had no endothermic curve. As the content of MC increased, the endothermic curve of PVA became broader and its peak shifted to lower temperatures. PVA blends with increased amount of MC; the endothermic peak of PVA does not disappear for blends of MC contents up to $10 \%$. The depression of the melting temperature and the peak broadening indicate that the ordered association of the PVA molecules was decreased by the presence of MC. As shown for the gamma irradiated blends, the melting temperature of PVA was slightly decreased by increasing irradiation dose or MC contents. The melting temperature depression is caused by morphological and chemical modifications. The morphological changes involve the thickness of the crystallites and the degree of crystallinity. The melting temperature depression and the peak broadening suggest that the PVA molecules are highly constrained by the entanglement of the two polymers due to the crosslinking of the blend by gamma radiation.

\section{Conclusions}

In this work, poly(vinyl alcohol) PVA as a hydrophilic polymer was blended with low ratios of the hydrophobic polymer methyl cellulose (MC); potentially these blends could be used in drug delivery field. However, we were interested in studying the kinetic parameters of gamma irradiated PVA/MC blends by three methods. The activation energy $\left(E_{a}\right)$ with maximum $r^{2}$ value of the gamma irradiated PVA/MC blends were determined by Coats-Redfern method is comparable with the Broido method and the approximation method of Horowitz-Metzger. However, activation energy $\left(\mathrm{E}_{\mathrm{a}}\right)$ with maximum $r^{2}$ value by Horowitz-Metzger was slightly higher than those calculated by the Coats-Redfern and the Broido methods. From the results obtained by the three methods, it is observed that the gamma irradiated PVA/MC blends possessed higher energy of activation when compared with that of unirradiated blends depending on the stage of thermal decomposition. This is may be due to higher crosslink density of PVA component. 
Military Technical College

Kobry El-Kobbah,

Cairo, Egypt

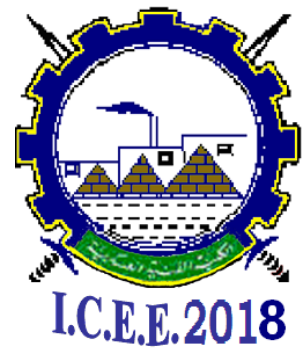

$9^{\text {th }}$ International Conference

on

Chemical \& Environmental

Engineering

3-5 April 2018

\section{References}

[1] J.S. Parka, J.W. Parkb, E. Ruckensteinc. Thermal and dynamic mechanical analyses of PVA/MC blend hydrogels. Polymer 42 (2001) 4271-4280

[2] M. M. Senna, S. Salmieri, A.. El-Naggar, A..Safrany, M. Lacroix. Improving the Compatibility of Zein/Poly(vinyl alcohol) Blends By Gamma Irradiation and Graft Copolymerization of Acrylic Acid. Journal of Agricultural and Food Chemistry 58, 2010, 4470-4476.

[3] H. M. Nizam El-Din and A. Wahab M. El-Naggar. Effect of Gamma Irradiation on the Physical Properties and Dyeability of Poly(vinyl butyral) blends with Polystyrene and Poly(ethylene glycol). Polymer Composites , 29, (2008) 1364-1371.

[4] M. M. Senna, F. M. Hossam and A. Wahab M.El-Naggar. Compatibilization of lowdensity polyethylene/plasticized strarch blends by reactive compounds and electron beam irradiation. Journal of Applied Polymer Science, 106, 4202 (2007).

[5] H. M. Nizam El-Din, A. Wahab M. El-Naggar, F. I. Ali. Thermal decomposition behavior of $\gamma$-irradiated poly(vinyl acetate)/poly(methyl methacrylate) miscible blends. Journal of Applied Polymer Science, 99, (2006)1773.

[6] [Martien FL. Encyclopedia of polymer science and engineering, Vol.17. New York: Wiley, 1986. p.167.

[7] Be Miller JN. Encyclopedia of polymer science and engineering, Vol. 7. New York: Wiley, 1986. p. 601.

[8] M. Hirrien, J. Desbrieres, M.Rinaudo, Carbohydr Polym 31,1996; 243.

[9] Sarkar N, Walker LC. Carbonhydr Polym 1995;27:177.

[10] H. Hirrien, C. Chevillard, J. Desbrieres, M. Rinaudo, Polymer 39,1998; 6251.

[11] J. Desbrieres, M. Hirrien, SB Ross-Murphy. Polymer 41, 2000; 2451.

[12] M. Liu, R. Cheng, R. Quian. J Polym Sci, Polym Phys Ed 1995; 33:1731.

[13] F. Horkay, M. Zrinyi. Macromolecules 15,1982;:1306.

[14] E. Tomita, Y. Ikeda, J Polym Sci, Part A 35: 1997;3553.

[15] V. Gimenez, JA. Reina, A. Mantecon, V. Cadiz. Polymer 40:1999; 2759.

[16] C.K. Yeom, K.H. Lee. J Membr Sci 109,1996;:257.

[17] K.J. Kim, S.B. Lee, N.W. Han. Polym J 25,1993;:129.

[18] L. Mayol, D. De Stefanoa, F. De Falcoa, R. Carnuccio,M. C. Maiuri, G. De Rosa. Effect of hyaluronic acid on the thermogelation and biocompatibilityof its blends with methyl cellulose. Carbohydrate Polymers 112 (2014) 480-485

[19] E.S.M. Negimb, Zh. A. Nurpeissovaa, R.A. Mangazbayeva, J.M. Khatib, C. Williams, G.A. Mun. Effect of $\mathrm{pH}$ on the physico-mechanical properties and miscibility of methyl cellulose/poly(acrylic acid) blends. Carbohydrate Polymers 101 (2014) 415-422. 
Military Technical College

Kobry El-Kobbah,

Cairo, Egypt

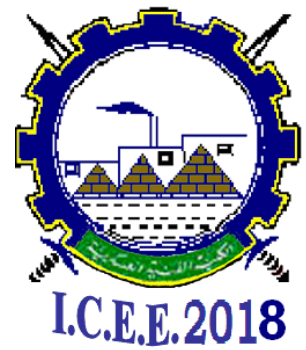

$9^{\text {th }}$ International Conference on

Chemical \& Environmental

Engineering

3-5 April 2018

[20] G.Anita, S. Sullad, L. Manjeshwar, T. M. Aminabhavi and P. N. Naik. Microspheres of Poly (vinyl alcohol) and Methyl Cellulose for the Controlled Release of Losartan Potassium and Clopidogrel Bisulphate. American Journal of Advanced Drug Delivery.

[21] A.Kumar, Y. Singh, N., N. Kant Bhardwaj, Veena Choudhary Synthesis and characterization of methylcellulose/PVA based porous composite.

Carbohydrate Polymers 88 (2012) 1364- 1372.

[22] Coats, A.W.; Redfern, J.P. Kinetic parameters from thermogravimetric data. Nature, 1964, 201, 68.

[23] A. Broido, J Polym. Sci., Part A-2: Polym Phys 1969, 7, 1761.

[24] H.W.Horowitz, G.Metzger, A new analysis of thermogravimetric traces. Anal. Chem. 35, 1963, 1464.

[25] A.Chapiro, Radiation Chemistry of Polymeric Systems; Interscience: New York, 22-81, 1962.

[26] A. Chapiro, Radiat. Res. Suppl., 13(1958), 198.

[27] O.Saito, J. Phys. Soc. Jpn, 13(1958), 1451.

[28] O.Saito, J. Phys. Soc. Jpn, 3, (1958) 1465.

[29] S. G. Abd Alla, H. M. Nizam El-Din, A. Wahab M. El-Naggar. Electron Beam Synthesis and Characterization of Poly(vinyl alcohol)/Montmorillonite Nanocomposites. J Appl Polym Sci 102: 2006, 1129-1138.

[30] S. Gopalakrishnan, R. Sujatha. Comparative thermoanalytical studies of polyurethanes using Coats-Redfern, Broido and Horowitz-Metzger methods. Der Chemica Sinica, 2(5): 2011, 103-117.

[31]. T.Ozawa, Bull. Chem.Soc.Jpn., 1965, 38,1881-6.

[32]. H.L. Friedman, J Polym Sci., Part C Polym Symposia., 6, 1964,183-95.

[33]. W.L.Chang, J. Appl. Polym. Sci., 53, 1994,1759-69.

[34]. H.E. Kissinger, Anal Chem., 29, 1957, 1702-6.

[35] K. W. Whittin,; K. D Gailelt,. General Chemistry with Quantitative Analysis; Saunders: Philadelphia, 1981; p 372.

[36] V Sriram, S Subramari, G Radhakrishan (2001) Polym Int 50:1124 486

[37] F Sundari, M Isni J Appl Polym Sci 28: (1983) 3123

[38] J Bicrano In Prediction of polymer properties, Marcel Dekker, N Y, 16(1993): 332

[39] B.Ghanbarzadeh, H.Almasi, A.A. Entezami. Physical properties of edible modified starch/carboxymethyl cellulose films. Innovative Food Science and Emerging Technologies 11 (2010) 697-702. 
Military Technical College Kobry El-Kobbah, Cairo, Egypt

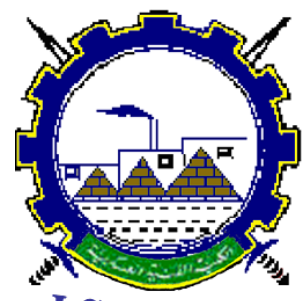

I.C.E.E.2018 $9^{\text {th }}$ International Conference on

Chemical \& Environmental

Engineering

3-5 April 2018

Table 1: Weight loss (\%) at different decomposition temperatures of PVA/MC blend of different ratios, before and after gamma irradiation to various doses

\begin{tabular}{lllllll}
\hline PVA/ MC & Dose & \multicolumn{6}{l}{ Weight loss $(\%)$} \\
\cline { 2 - 7 } Blends (\%) & $(\mathrm{kGy})$ & $100^{\circ} \mathrm{C}$ & $200^{\circ} \mathrm{C}$ & $300^{\circ} \mathrm{C}$ & $400^{\circ} \mathrm{C}$ & $500^{\circ} \mathrm{C}$ \\
\hline $100 / 0$ & 0 & 0.21 & 2.48 & 23.38 & 69.86 & 85.38 \\
\cline { 2 - 7 } & 10 & 2.13 & 5.35 & 23.53 & 60.85 & 83.08 \\
\cline { 2 - 7 } & 20 & 0.00 & 1.65 & 10.70 & 56.24 & 77.59 \\
\cline { 2 - 7 } & 40 & 0.00 & 1.71 & 11.16 & 50.50 & 75.13 \\
\hline $95 / 5$ & 0 & 1.44 & 3.36 & 41.15 & 65.35 & 76.54 \\
\cline { 2 - 7 } & 10 & 26.5 & 16.84 & 61.50 & 80.40 & 90.66 \\
\cline { 2 - 7 } & 20 & 82.1 & 5.26 & 22.80 & 56.11 & 78.33 \\
\cline { 2 - 7 } & 40 & 81.1 & 3.01 & 18.84 & 57.85 & 83.78 \\
\hline $90 / 10$ & 0 & 96.6 & 15.29 & 51.44 & 77.94 & 90.91 \\
\hline & 10 & 90.3 & 2.52 & 37.34 & 69.08 & 79.59 \\
\cline { 2 - 7 } & 20 & 8.62 & 19.75 & 38.68 & 70.79 & 90.15 \\
\hline & 40 & 3.69 & 9.91 & 55.02 & 76.83 & 88.66 \\
\hline
\end{tabular}

Table 2: Kinetic temperatures of PVA/MC blend of different ratios, before and after gamma irradiation at different doses.

\begin{tabular}{|c|c|c|c|c|}
\hline $\begin{array}{l}\text { PVA/MC } \\
\text { blends ( } \%)\end{array}$ & $\begin{array}{c}\text { EB } \\
\text { dose } \\
(\mathrm{kGy})\end{array}$ & $\begin{array}{l}\mathrm{T}_{\text {Onset }} \\
\left({ }^{\circ} \mathrm{C}\right)\end{array}$ & $\begin{array}{l}\mathrm{T}_{\text {Endset }} \\
\left({ }^{\circ} \mathrm{C}\right)\end{array}$ & $\begin{array}{l}\mathrm{T}_{\text {peak }} \\
\left({ }^{\circ} \mathrm{C}\right)\end{array}$ \\
\hline \multirow[t]{4}{*}{$100 / 0$} & 0 & 281 & 389 & 325 \\
\hline & 10 & 357 & 449 & 394 \\
\hline & 20 & 344 & 430 & 401 \\
\hline & 40 & 387 & 450 & 422 \\
\hline \multirow[t]{4}{*}{$95 / 5$} & 0 & 261 & 355 & 314 \\
\hline & 10 & 290 & 360 & 333 \\
\hline & 20 & 370 & 434 & 394 \\
\hline & 40 & 372 & 427 & 405 \\
\hline \multirow[t]{4}{*}{$90 / 10$} & 0 & 244 & 391 & 298 \\
\hline & 10 & 258 & 366 & 312 \\
\hline & 20 & 335 & 382 & 358 \\
\hline & 40 & 321 & 395 & 368 \\
\hline
\end{tabular}


Military Technical College Kobry El-Kobbah, Cairo, Egypt

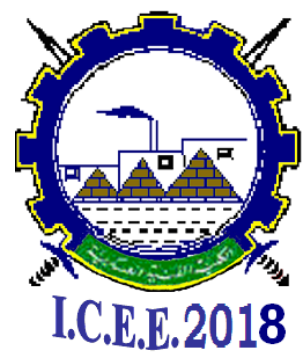

$9^{\text {th }}$ International Conference on

Chemical \& Environmental

Engineering

3-5 April 2018

Table 3: Energy of activation of the thermal decomposition of PVA/MC blends, before and after gamma irradiation at various doses, calculated according to the Coats-Redfern, Horowitz-Metzger and Broido equations with maximum $\mathrm{r}^{2}$ value.

\begin{tabular}{|c|c|c|c|c|c|c|c|}
\hline \multirow{3}{*}{$\begin{array}{l}\text { PVA/MC blends } \\
(\%)\end{array}$} & \multirow{3}{*}{$\begin{array}{l}\text { Dose } \\
\text { (kGy) }\end{array}$} & \multicolumn{6}{|c|}{ Activation energy $(\mathrm{kCal} / \mathrm{mol})$} \\
\hline & & \multicolumn{2}{|c|}{ Coats-Redfern } & \multicolumn{2}{|c|}{ Horowitz-Metzger } & \multicolumn{2}{|l|}{ Broido } \\
\hline & & $E_{a}$ & $r^{2}$ & $E_{a}$ & $r^{2}$ & $\mathrm{E}_{\mathrm{a}}$ & $r^{2}$ \\
\hline \multirow[t]{4}{*}{$100 / 0$} & 0 & 8.060 & 0.97801 & 9.286 & 0.97236 & 9.620 & 0.98946 \\
\hline & 10 & 10.613 & 0.97801 & 13.363 & 0.97783 & 11.889 & 0.95262 \\
\hline & 20 & 13.073 & 0.93430 & 14.362 & 0.93236 & 12.303 & 0.98667 \\
\hline & 40 & 13.307 & 0.99292 & 14.454 & 0.91105 & 12.899 & 0.97673 \\
\hline \multirow[t]{4}{*}{$95 / 5$} & 0 & 6.851 & 0.93887 & 8.449 & 0.98001 & 7.279 & 0.95558 \\
\hline & 10 & 7.161 & 0.93279 & 8.689 & 0.98505 & 8.284 & 0.96953 \\
\hline & 20 & 8.493 & 0.96902 & 9.922 & 0.93771 & 10.030 & 0.91282 \\
\hline & 40 & 12.289 & 0.98237 & 13.743 & 0.95040 & 10.616 & 0.99586 \\
\hline \multirow[t]{4}{*}{$90 / 10$} & 0 & 4.036 & 0.96357 & 5.537 & 0.99248 & 6.149 & 0.98512 \\
\hline & 10 & 6.158 & 0.93414 & 7.143 & 0.95731 & 7.110 & 0.97637 \\
\hline & 20 & 8.899 & 0.98487 & 8.361 & 0.92678 & 8.181 & 0.93679 \\
\hline & 40 & 11.153 & 0.96910 & 13.001 & 0.96323 & 11.481 & 0.91919 \\
\hline
\end{tabular}


Military Technical College

Kobry El-Kobbah,

Cairo, Egypt
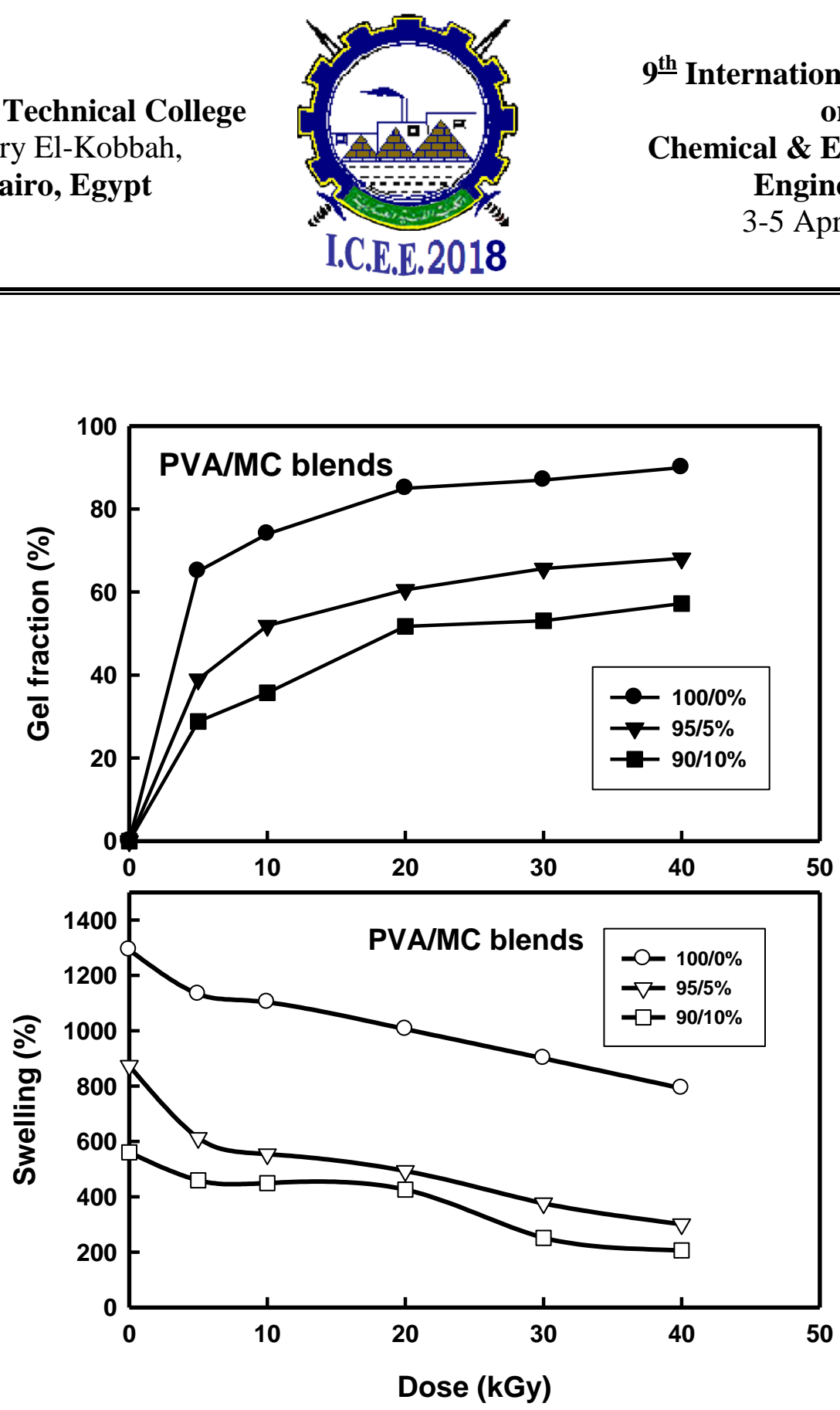

Fig.1. Effect of gamma irradiation dose on the gel fraction (\%) and swelling (\%) in water at room temperature and $\mathrm{pH}$ of 7 of PVA/MC blends of different ratios. 
Military Technical College

Kobry El-Kobbah,

Cairo, Egypt

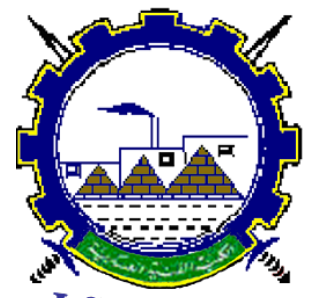

I.C.E.E.2018 $9^{\text {th }}$ International Conference on

Chemical \& Environmental

Engineering

3-5 April 2018

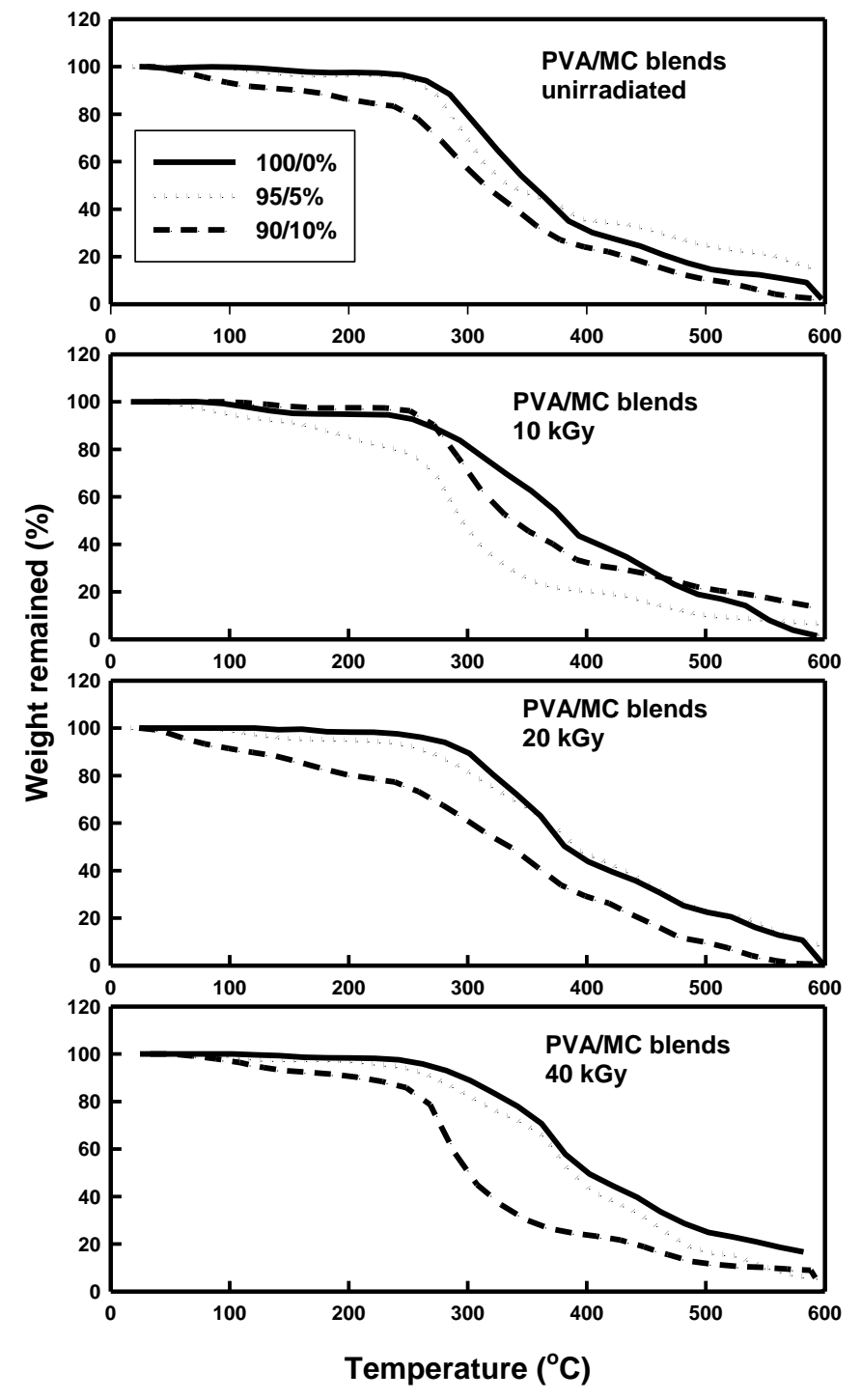

Fig.2. TGA thermogram curves of PVA/MC blends, before and after gamma irradiation at various doses. 
Military Technical College

Kobry El-Kobbah,

Cairo, Egypt

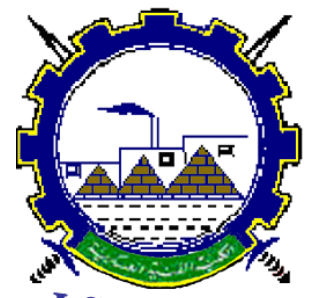

I.C.E.E.2018 $9^{\text {th }}$ International Conference on

Chemical \& Environmental

Engineering

3-5 April 2018

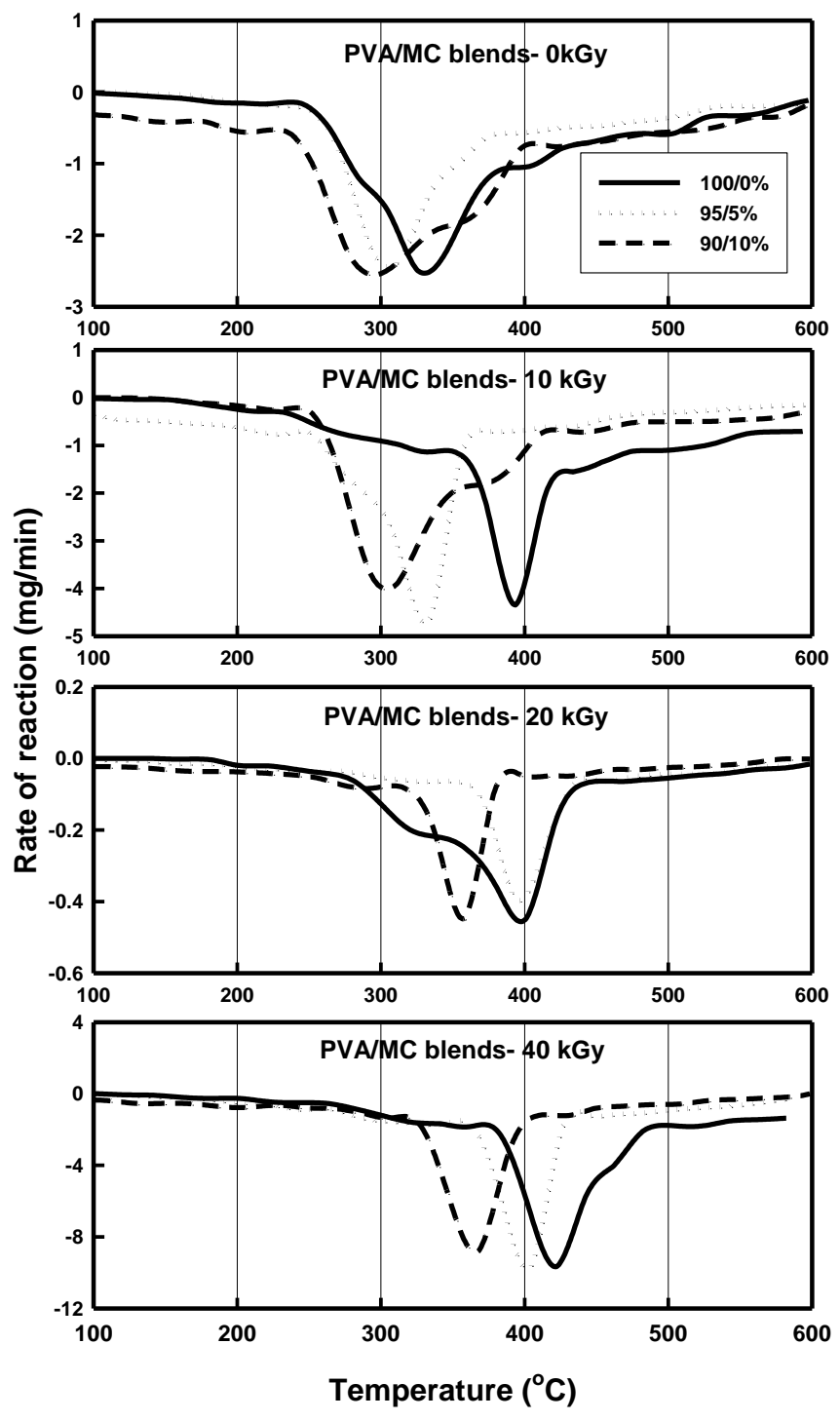

Fig.3. Rate of thermal decomposition curves of PVA/MC blends, before and after gamma irradiation at various doses. 
Military Technical College

Kobry El-Kobbah,

Cairo, Egypt

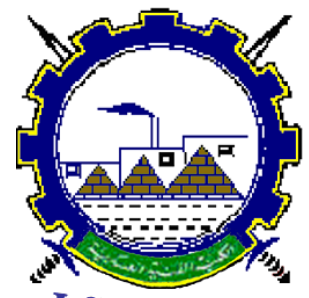

I.C.E.E.2018 $9^{\text {th }}$ International Conference on

Chemical \& Environmental

Engineering

3-5 April 2018
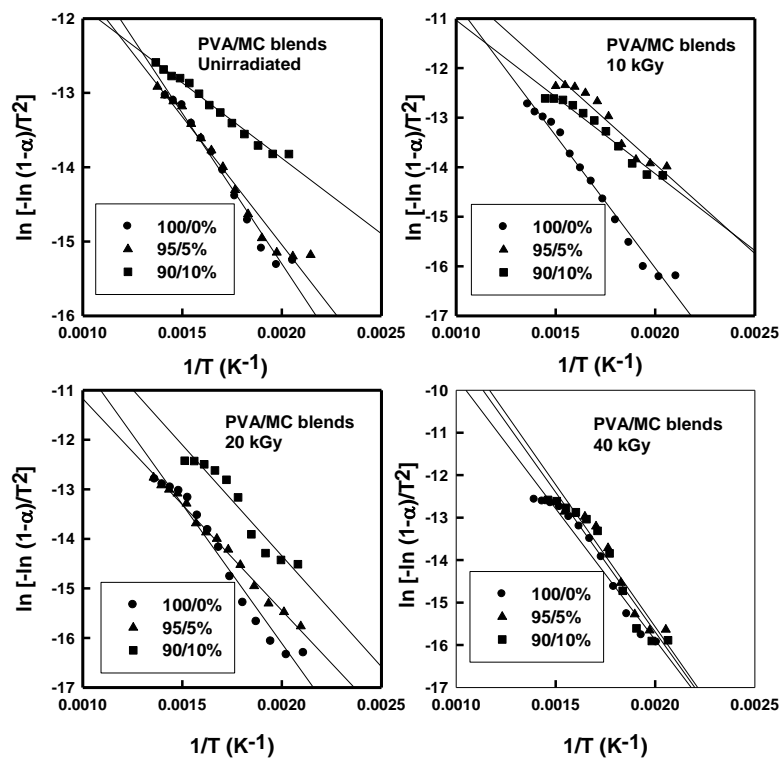

Fig.4. Plots of $\log \left[g(\alpha) / T^{2}\right]$ vs. $1 / T$ for gamma irradiated PVA/MC blends at different doses according to the Coats-Redfern equation.
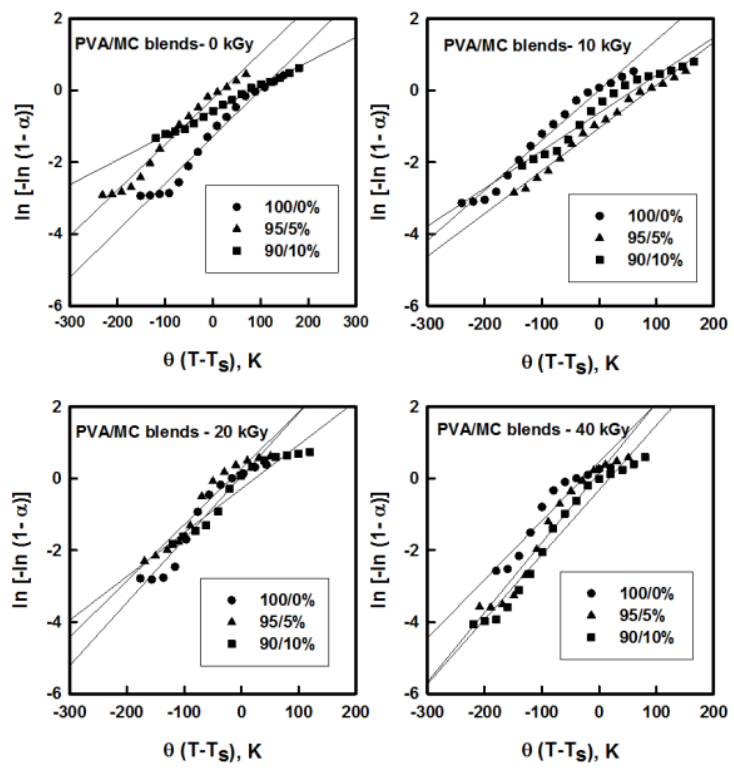

Fig.5. Plots of $\ln \ln \left(W_{\mathrm{o}}\right) /\left(\mathrm{W}_{\mathrm{t}}\right)$ vs. $\theta$ where $\theta=T-T_{\mathrm{s}}$ for gamma irradiated PVA/MC blends at different doses, according to the Horowitz-Metzger equation. 


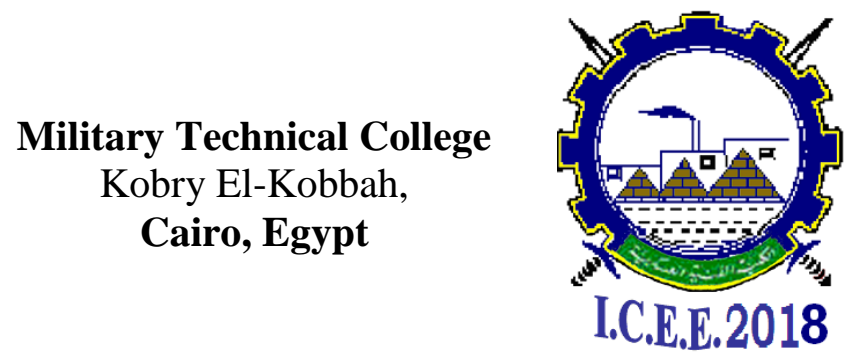

$9^{\text {th }}$ International Conference on

Chemical \& Environmental

Engineering

3-5 April 2018

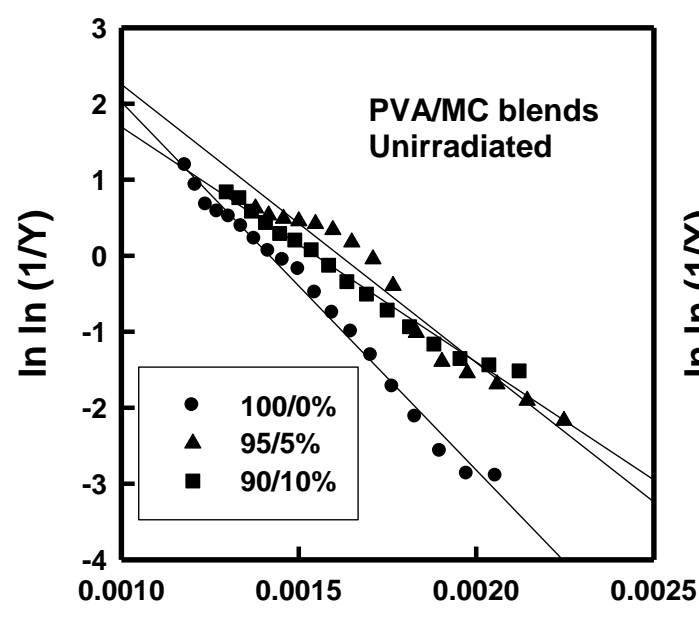

$1 / \mathrm{T}(\mathrm{K}-1)$
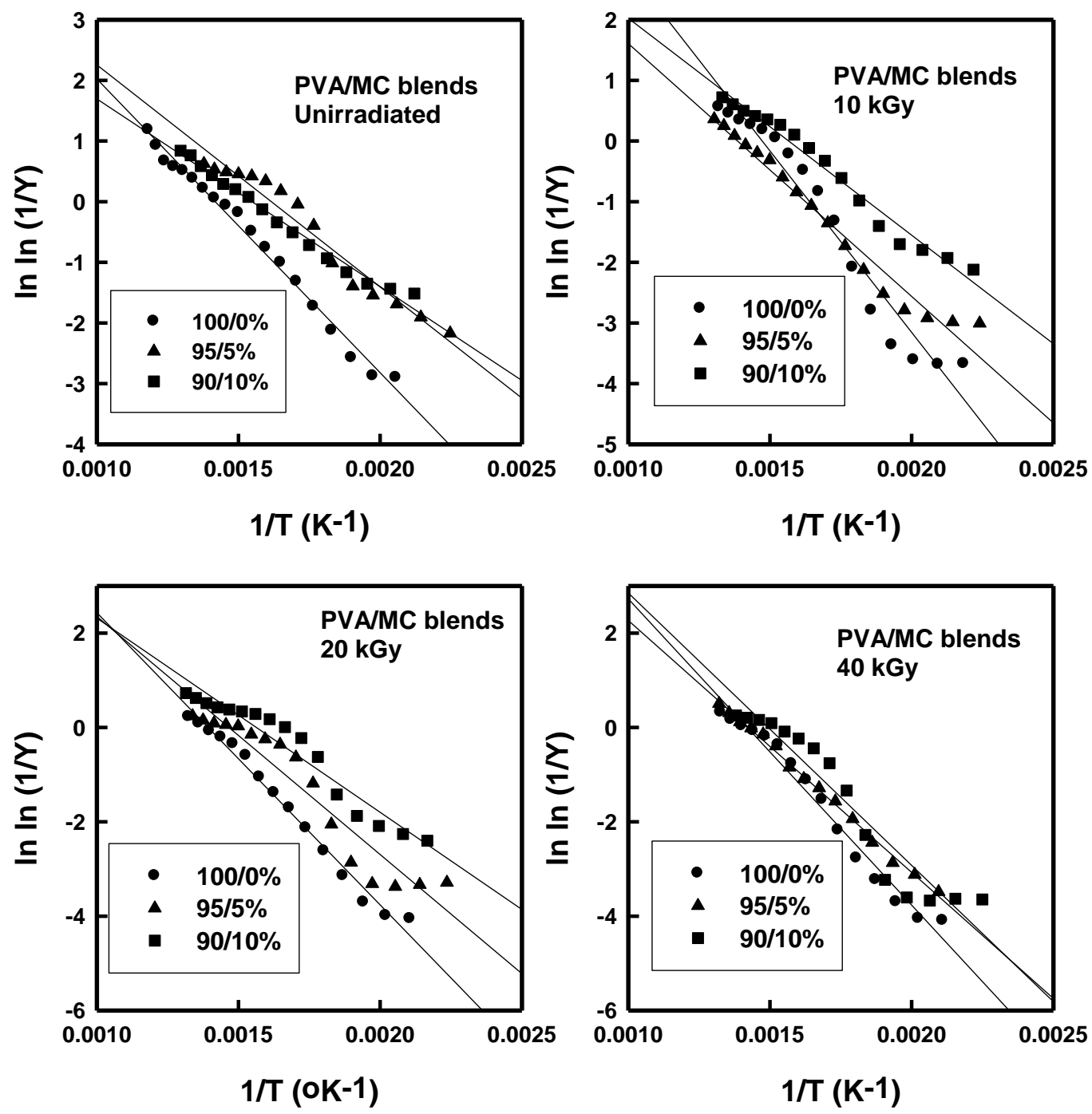

Fig.6. Plots of $\ln \ln (1 / Y)$ vs. $1 / T$ where $Y=\left(W_{t}-W_{\infty}\right) /\left(W_{0}-W_{\infty}\right)$ for gamma irradiated PVA/MC blends at different doses according to the Broido equation. 
Military Technical College

Kobry El-Kobbah,

Cairo, Egypt

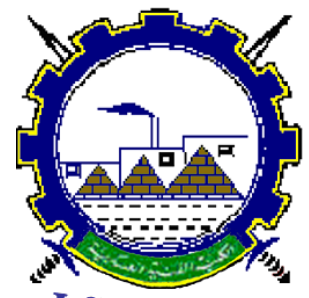

I.C.E.E.2018 $9^{\text {th }}$ International Conference on

Chemical \& Environmental

Engineering

3-5 April 2018

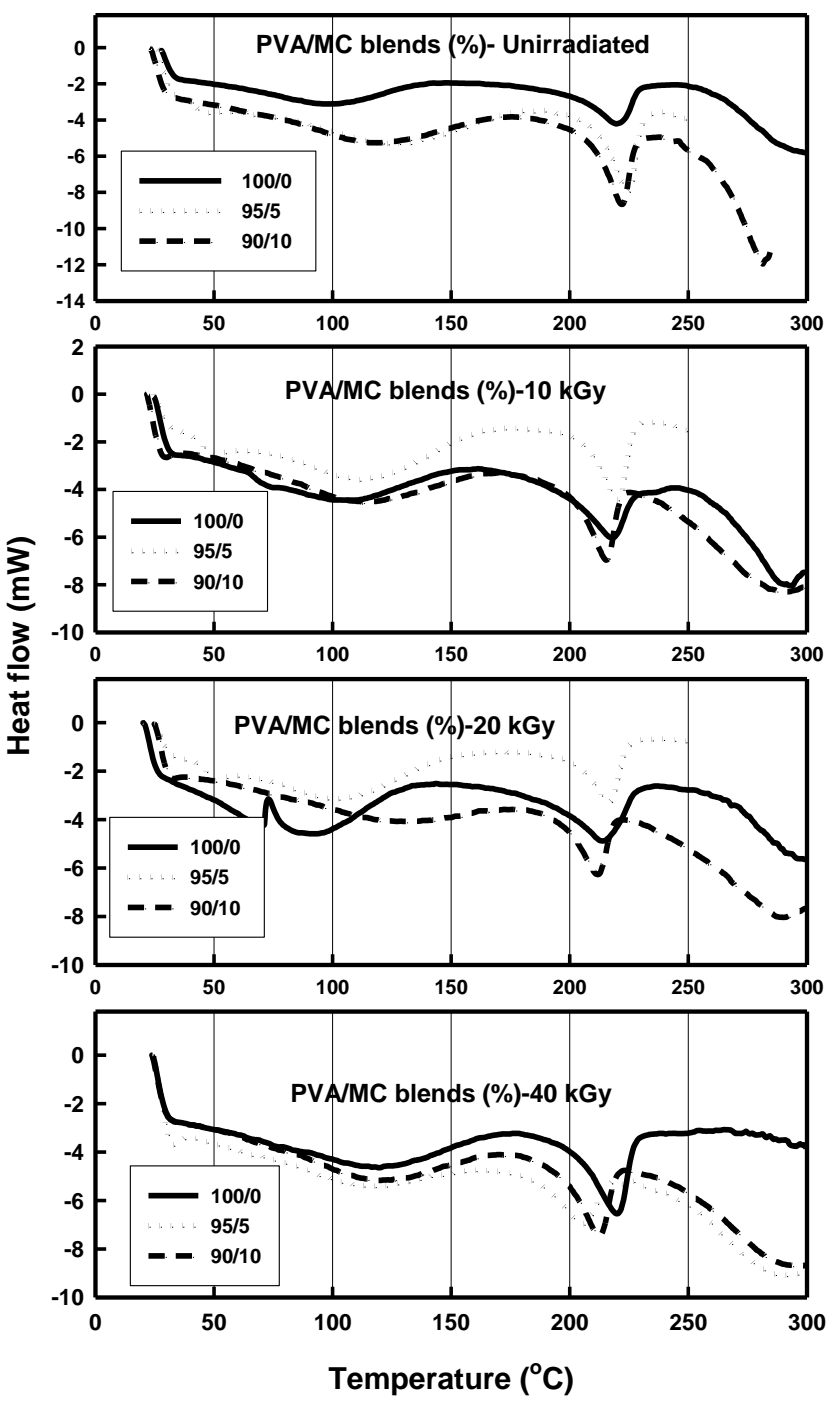

Fig.7. DSC thermograms of gamma irradiated PVA/MC blends at different doses. 